\title{
Treatment of dental erosion caused by intrinsic and extrinsic etiology: a case report
}

\author{
Gyeong-Je Lee', Soo-Yoon Jin', Hee-Jung Kim¹, Jeong-Bum Min²* \\ 'Department of Prosthodontics, School of Dentistry, Chosun University, Gwangju, Republic of Korea \\ ${ }^{2}$ Department of Conservative Dentistry, School of Dentistry, Chosun University, Gwangju, Republic of Korea
}

Dental erosion is defined as tooth structure loss by acidic chemical substance. It is caused by extrinsic factors such as acidic foods, drugs, and working environments, and also intrinsic factors such as gastric acid regurgitation in gastro-esophageal disorder or intensive vomiting in bulimia nervosa. These lesions can be treated with direct resin filling, laminate or full contour crown depending on the intensity of clinical problem. This is a case report about treatment of rare clinical case: labial erosion of anterior tooth caused by frequent intake of acidic fruit and palatal erosion of anterior tooth caused by intensive vomiting in bulimia nervosa. (J Dent Rehabil Appl Sci 2017;33(1):42-6)

Key words: dental erosion; zirconia; bulimia nervosa

\section{서론}

치아 경조직의 손상은 자연적으로 재생이 되지 않기 때 문에 연령이 증가함에 따라 누적되는 양상을 보인다. ${ }^{1}$ 이 러한 치아 경조직의 손상은 크게 우식성 세균 부산물 에 의해 발생되는 치아우식, 그리고 비우식성 치아상 실로 구분된다. 이 중 비우식성 치아상실은 다시 마모 (abrasion), 교모(attrition), 굴곡파절(abfraction), 그리고 부식(erosion)으로 구분되며 특수한 경우로 치아의 흡수 (resorption)가 포함되기도 한다. ${ }^{2}$ 이 중 부식은 세균이 아닌 화학적 자극에 의한 치아조직의 점진적 흡수로 정 의된다. ${ }^{3}$ 생활방식의 변화에 따라 현대인에 많이 발생되 며 이러한 부식은 영구치가 맹출 되는 즉시 발생한다고 알려져 있다. ${ }^{4}$ 이러한 부식의 원인에 대해서는 비교적 명 확히 밝혀져 있으며 크게 외인성 원인과 내인성 원인으
로 나뉜다. 외인성 요인으로는 공기 중에 산이 노출된 작 업환경, ${ }^{5}$ 약물, ${ }^{6}$ 수영장의 염소, ${ }^{7}$ 음식(포도주, 산성의 과 일주스, 탄산음료, 과일) 등에 의해 야기된다고 알려져 있 다. ${ }^{8}$ 그리고 내인성 원인으로는 위장과 장애에 의한 의 도하지 않은 위산 역류 및 신경성 식욕부진증(anorexia nervosa), 신경성 식욕항진증(bulimia nervosa) 등이 지목 되고 있다. ${ }^{9}$

본 증례는 빈번한 산성 과일(자몽)의 섭취 및 신경성 식 욕항진증으로 인한 잦은 구토로 상악 전치부의 순측 및 구개측 모두에서 심한 부식이 발생한 경우로 부식의 원 인 중 내인성 원인과 외인성 요인이 복합되어 나타난 드 문 증례였다. 부식에 대한 임상적 심각도에 따른 분류 기 준에 근거하여 지르코니아 소재의 도재전장관 수복으로 치료하였다. 


\section{증례보고}

본 증례의 환자는 45 세 여자 환자로서 하악 구치부 재 보철 치료를 위해 본원 타과로부터 의뢰되어 내원하였다. 기존 하악 우측 제 2 소구치와 제 2 대구치를 지대치로 하는 주조 금합금 고정성국소의치 중 원심 지대치에서 이차우 식증으로 인한 치관-치근 분리 및 근심지대치를 축으로 한 보철물의 동요, 방사선 사진 상의 치근 이개부에 연접 한 명확한 우식이 관찰되어 해당 치아에 대한 발치가 계 획되었다. 그러나 전방의 지대치인 하악 우측 제 2 소구치 에서 치주인대 비후 소견은 있었으나 치조백선의 건전성 이 확보된 바 재보철 수복 후 보존하기로 결정하였고, 발 치 부위 및 기존 무치악 부위에 대한 임플란트 식립을 계 획하였다. 이상의 본과에 내원하게 된 구치부의 불편감 이외에도 치아의 전반적인 부식 및 굴곡파절 소견이 발견 되는 바 이에 대한 설명을 환자에게 하였다. 이에 환자도 이 문제에 대해 이미 인식하고 있었으며 심미적 불만족 및 찬물에 지각과민증으로 이에 대한 치료도 함께 진행 하기로 하였다.

구강검진 결과 구내 전반에 걸쳐 굴곡파절, 치아의 마 모 및 부식 등의 비우식성 치아상실이 분포하고 있었으 며, 특히 상악 전치의 경우 구개측과 순측 모두의 심한 부 식 및 절단연에 많은 치질의 손상이 관찰되었다. 또한 치 아의 일부 치질 손실이 심한 부위에서는 광택 없는 진한 갈색의 착색이 있는 반면 나머지 부위는 광택이 있는 양 상을 나타내었다.

이 환자는 예전부터 신 과일(자몽)을 하루에 10 개 이상 섭취를 했으며, 현재는 시린 증상으로 중단하였지만 신 맛의 음료를 매우 자주 마셨을 뿐 아니라 다이어트를 위

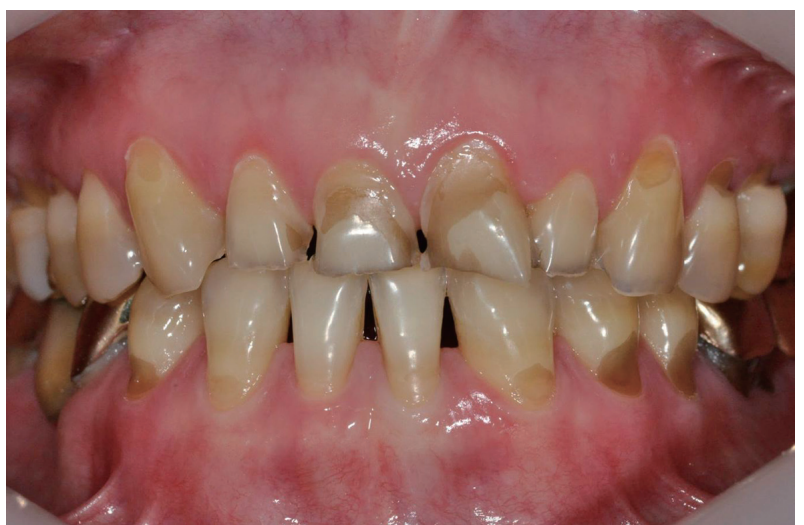

Fig. 1. Intraoral view of $1^{\text {st }}$ visit.
해 음식을 섭취 후 의도적으로 구토를 자주 하였다고 하 였다. 이상의 임상적 증상과 병력을 종합하여 잘못된 식 습관 및 구토유도로 인한 부식에 의한 비우식성 치아 상 실로 진단하였다(Fig. 1).

본 환자의 경우, 치질의 손상이 상악 전치의 순측 및 구 개측은 물론 절단연까지 치질의 거의 대부분에서 상아질 의 노출이 관찰되는 심한 치질의 손실이 관찰되었기 때문 에 레진 충전 보다는 도재전장관으로 수복하기로 결정하 였다.

진단납형 형성 후 환자 교육 및 동의서 작성을 시행하 였으며 이 진단납형과 부가중합형 실리콘(Exafine, GC, Tokyo, Japan)을 이용하여 지대치 삭제를 위한 가이드 를 제작 및 자가중합형 아크릴릭 레진(MIKY, NISSIN, Kyoto, Japan)으로 임시치관을 제작하였다. 지대치 형성 후 직-간접법으로 임시치관 재이장하여 장착하였고, 임 시치관 상태에서 심미성과 발음 등을 2 개월 간 확인한 후 최종 인상 채득하였다. 초경석고(FujiRock, GC, Tokyo, Japan)를 이용하여 주모형을 제작하고 이를 다시 모형 스캐너(Zirkonzhan Arti600, Zirkonzhan, Gais, Italy) 를 이용한 모형의 디지털화 후 전용 $\mathrm{CAD}($ Zirkonzhan Exocad, Zirkonzhan, Gais, Italy) 및 CAM(Zirkonzhan M5, Zirkonzhan, Gais, Italy)를 이용하여 지르코니아 블 록(Prettau Zirconia, Zirkonzhan, Gais, Italy)을 절삭 가 공하였다. 지르코니아 소성 후 코핑의 시적 후 장석계 도 재(E-max, Ivoclar Vivadent, Amherest, USA)를 적층 가 공하였다. 최종보철물을 임시합착 시행하고 1 개월 간 별 다른 문제가 없어 영구합착(RelyX UniCem, 3M ESPE, Seefeld, Germany) 하였으며 6개월 간의 경과 관찰에서도 심미 및 기능적으로 만족할 만한 결과를 얻었다(Fig. 2, 3).

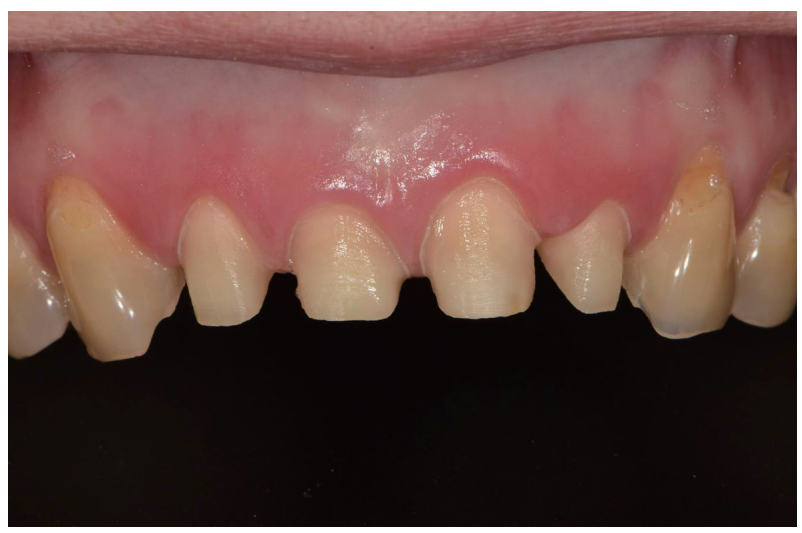

Fig. 2. Tooth preparation for zirconia all ceramic crown. 


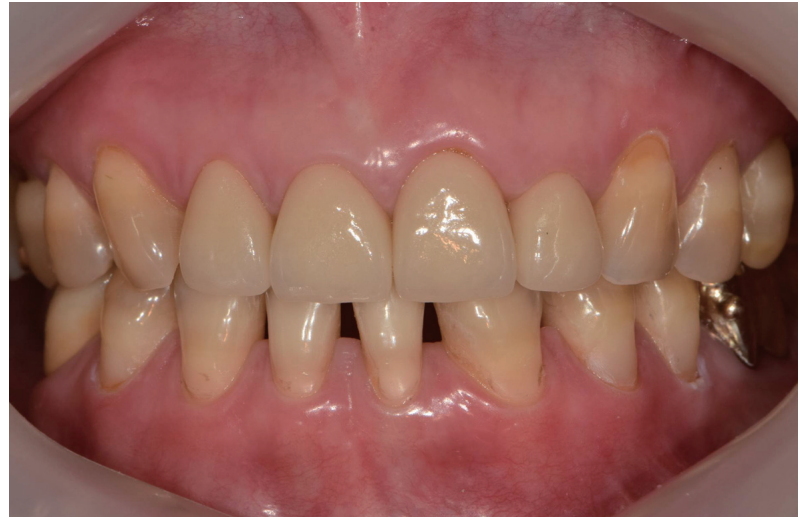

Fig. 3. Intraoral view of after the treatment.

\section{고찰}

비우식성 치질손실의 일종인 부식은 주로 $\mathrm{pH} 5.5$ 미만 의 화학적 인자와 치아의 접촉 시 발생한다고 알려져 있 다. ${ }^{10}$ 대부분의 음료가 $\mathrm{pH} 4$ 미만의 산도를 보이고, 신맛 이 나는 과일의 경우 특히 강한 산도를 가지고 있어 치아 의 부식을 많이 야기하는 것으로 알려져 있다. ${ }^{11}$ 그러나 수종의 산성 음료에 발치된 치아를 침전시켜 무게의 변 화를 측정함으로써 산도가 치아부식에 비치는 영향에 대 해 분석한 최근의 한 연구에서는 산도와 치아부식의과의 상관관계가 없는 것으로 나타나 이 부분에 대한 추가 연 구가 필요할 것으로 생각된다. ${ }^{12}$

부식은 상기한 바와 같이 외인성 요인에 의해 발생되 기도 하지만 위산의 역류에 의한 내인성 요인에 의해 발 생되기도 한다. ${ }^{2}$ 위산의 경우 $\mathrm{pH} 1.0$ - 3.0 정도의 강산으 로 의도적이든(신경정신학적 원인) 의도적이지 않든(체성 원인) 치아에 미치는 손상이 클 수 밖에 없다. 본 환자의 경우, 음식은 섭취하되 다이어트를 위해 의도적으로 구 토를 유도한 경우(폭식증, bulimia nervosa)로 음식과 다 이어트에 대해 지나친 연관을 지어 음식 자체를 거부하 지만 간혹 폭식 후 야간에 은밀하게 구토를 유도하는 경 우(거식증, anorexia nervosa)과는 구분이 필요한 경우이 다. ${ }^{4}$

이상에서 기술한 원인들에 의해 치아가 산에 노출되 게 되면 법랑질의 미세경도의 감소가 발생하게 되고, 일 단 법랑질의 부식으로 인해 상아질이 노출된다면 치질의 손상은 가속화 된다. 법랑질이 산에 노출된 경우 이온화 된 산이 법랑질 결정을 용해시키고, 이로 형성된 벌집 모 양의 구조를 형성하게 된다. 이 다공성 구조로 이온화되
지 않은 산이 다시 침투하게 되어 이온을 밖으로 방출하 게 되고 주변의 산성을 낮추게 된다. 만일 이 과정에서 구 강 내에 불소이온이 많은 경우 불화인회석이 되어 오히 려 내산성이 증가된 법랑질을 형성하게 된다. 그에 반해 상아질의 경우 수산화인회석의 크기가 법랑질보다 작아 산에 의한 영향을 많이 받게 되고 법랑질과의 부식의 정 도가 차이 나게 된다. ${ }^{13}$ 게다가 그 부분에 교합간섭이 존 재한다면 부식이 훨씬 더 심하게 진행된다. ${ }^{14}$ 이러한 이유 로 본 환자에서 일부분에서는 광택의 소실 및 착색이 나 타나고 다른 부분에서는 광택이 나는 표면을 갖게 되었 다고 생각된다.

부식에 의해 치질이 손상된 경우 치료의 목표는 지각과 민 감소, 손상된 치질의 회복 그리고 심미성의 회복이 된 다. ${ }^{7}$ 치료법으로는 복합레진수복, 라미네이트 비니어, 그 리고 전장관 수복이 있다. 본 증례의 경우에는 지르코니 아 도재전장관 수복으로 치료를 진행했는데 그 근거는 해당 치아들이 전장관 형성을 위한 지대치 형성을 해 놓 은 것으로 보일 정도로 치질의 손상이 심한 점, Eccles ${ }^{15}$ 가 제시한 임상적 심각도에 따른 분류 기준 상 최고 등 급에 해당되는 점을 들 수 있다. 또한 지르코니아 소재의 보철을 제작한 이유는 치질의 순측-구개측 방향의 치질 손실이 심할 뿐 아니라. 전치 절단연도 심한 손상이 관찰 되는 바 대합치와의 편심위 교합가능성을 전제하고 지대 치의 순측-구개측 삭제량이 비교적 작을 뿐 아니라 대합 치의 교모 방지에도 유리한 지르코니아 소재의 보철물을 제작하기로 결정하였다. ${ }^{16,17}$

치아의 부식은 원시인류에서도 발견되기는 하나 그 발 병률이 점차 증가되는 추세여서 그 문제점이 크다고 볼 수 있다. 또한 치아경조직의 특성상 재생되지 않아 손상 이 누적되는 양상을 보이는데다 지난 세기에 비해 늘어 난 청량 음료 등 산성의 음료의 소비가 늘어간 것과 더불 어 부식이 발생이 어린 연령층에서 빠르게 증가된다는 점 에서 이에 대한 깊은 관심이 필요할 것으로 생각된다.

\section{결론}

부식은 세균이 아닌 화학적 물질에 의해 치아조직이 손 상되는 것으로 산성의 음식물이나 약물, 또는 위산에 의 해 발생된다. 이로 인해 치아의 지각과민, 치질의 손상, 심미성의 상실 등의 문제가 발생하며 증상의 정도에 따 라 레진 충전, 라미네이트 수복 또는 전장관 수복 등의 치 료가 필요하다. 


\section{References}

1. Pintado MR, Delong R, Ko CC, Sakaguchi RL, Douglas WH. Correlation of noncarious cervical lesion size and occlusal wear in a single adult over a 14-year time span. J Prosthet Dent 2000;84:436-43.

2. Imfeld T. Dental erosion. Definition, classification and links. Eur J Oral Sci 1996;104:151-5.

3. Almeida e Silva JS, Baratieri LN, Araujo E, Widmer N. Dental erosion: understanding this pervasive condition. J Esthet Restor Dent 2011;23:205-16.

4. Valena V, Young WG. Dental erosion patterns from intrinsic acid regurgitation and vomiting. Aust Dent J 2002;47:106-15.

5. Lynch JB, Bell J. Dental erosion in workers exposed to inorganic acid fumes. Br J Ind Med 1947; 4:84-6.

6. Richards JR, Brofeldt BT. Patterns of tooth wear associated with methamphetamine use. J Periodontol 2000;71:1371-4.

7. Peampring C. Restorative management using hybrid ceramic of patient with severe tooth erosion from swimming: a clinical report. J Adv Prosthodont 2014;6:423-6.

8. Künzel W, Cruz MS, Fischer T. Dental erosion in Cuban children associated with excessive consumption of oranges. Eur J Oral Sci 2000;108: 104-9.

9. Bartlett DW, Evans DF, Smith BG. The relationship between gastro-oesophageal reflux disease and dental erosion. J Oral Rehabil 1996;23:289-97.

10. Järvinen VK, Rytömaa II, Heinonen OP. Risk factors in dental erosion. J Dent Res 1991;70:942-7.

11. Willershausen B, Callaway A, Azrak B, Duschner H. Influence of apple juice on human enamel surfaces of the first and second dentition - an in vitro study. Eur J Med Res 2008;13:349-54.

12. West NX, Maxwell A, Hughes JA, Parker DM, Newcombe RG, Addy M. A method to measure clinical erosion: the effect of orange juice consumption on erosion of enamel. J Dent 1998; 26:329-35.

13. Shipley S, Taylor K, Mitchell W. Identifying causes of dental erosion. Gen Dent 2005;53:73-5.

14. Cardoso AC, Canabarro S, Myers SL. Dental erosion: diagnostic-based noninvasive treatment. Pract Periodontics Aesthet Dent 2000;12:223-8.

15. Eccles JD. Dental erosion of nonindustrial origin. A clinical survey and classification. J Prosthet Dent 1979:42:649-53.

16. Edelhoff D, Sorensen JA. Tooth structure removal associated with various preparation designs for anterior teeth. J Prosthet Dent 2002;87:503-9.

17. Jung YS, Lee JW, Choi YJ, Ahn JS, Shin SW, Huh JB. A study on the in-vitro wear of the natural tooth structure by opposing zirconia or dental porcelain. J Adv Prosthodont 2010;2:111-5. 


\section{외인성 및 내인성 요인에 의한 치아부식에 대한 치료 증례}

\section{이경제 ${ }^{1}$, 진수윤 ${ }^{1}$, 김희중 ${ }^{1}$, 민정범2*}

${ }^{1}$ 조선대학교 치과대학 치과보철학교실

${ }^{2}$ 조선대학교 치과대학 치과보존학교실

부식이란 산성의 화학적 물질에 의한 치아 경조직의 손상으로 정의된다. 이에 대한 원인인 산성 음식, 약물, 작업환경 등의 외부적 원인과 위장관 장애에 의한 위산의 역류나 거식증에 의한 의도적 구토의 내부적 원인에 의해 발생된다. 이는 임상 적 증상의 심각도에 따라 레진 충전, 라미네이트 수복 또는 전장관 수복으로 치료한다. 본 증례는 잦은 산성 과일의 섭취 로 인한 전치부 순측 부식 및 거식증으로 인한 의도적 구토로 전치부 구개측 부식이 일어난 드문 상황에 대한 치료이다.

(구강회복응용과학지 2017;33(1):42-6)

주요어: 치아부식; 지르코니아; 신경성 식욕항진증 